\title{
Application of Electrical Resistivity Method in Mapping Underground River Channels: A Case Study of Kabatini Area in the Kenyan Rift Valley
}

\author{
Aaron K. Waswa \\ Department of Geology, University of Nairobi, Kenya
}

Copyright $\mathrm{C} 2019$ by authors, all rights reserved. Authors agree that this article remains permanently open access under the terms of the Creative Commons Attribution License 4.0 International License

\begin{abstract}
Kabatini area is in Nakuru County which occurs in Kenya within the great Gregory rift valley. The area is bounded by longitudes 180900-181200 and latitudes 9971050-9971200 in UTM. This research aimed to investigate the possible occurrence of subsurface faults recharging Kabatini aquifer which is the primary source of groundwater for the residents of Nakuru town and its environs. Vertical electrical sounding and geological mapping methods were used to unravel this problem of subsurface fault occurrence in the area of study. Vertical Electrical Sounding data collected were analyzed using the computer-based inversion using EarthImager software, which allows the performance of automatic interpretation of the Schlumberger sounding curves to obtain the equivalent n-layer model from the apparent resistivity curve of each sounding. This procedure was used for all the sounding points collected in the study area, to obtain the equivalent apparent resistivity models of each sounding, their depths as well as thicknesses. The results indicate the occurrence of subsurface faults trending in the north-south direction which is proven by $\mathrm{K}-\mathrm{H}-\mathrm{K}, \mathrm{K}-\mathrm{H}-\mathrm{H}, \mathrm{Q}-\mathrm{H}-\mathrm{A}$, Q-H-Q. Depth iso-resistivity analysis shows that the fault plane is deeper than 165 meters below the surface.
\end{abstract}

Keywords Electrical Resistivity Method, Geophysical Mapping, Kenyan Rift Valley, Underground River Channel

\section{Introduction}

In the recent past, the water supply in Nakuru municipality, located within the Nakuru basin, has been characterized by chronic shortages affecting mainly residential and industrial functions. The municipality gets its water from both surface and underground water sources, and it has about six major water reservoirs, Kabatini aquifer being one of them. Kabatini water wells have been experiencing draw downs in water levels in the recent past, particularly during the dry season of the year. Kabatini area which is located in the northeastern part of Nakuru municipality is characterized by complex geology which has affected the ground water system. River Ngosur found to the north disappears into the ground in the northern part of Kabatini in Bahati plains. Many questions have come out in regard to the disappearance of this river into the subsurface. It is with this regards that we attempt to investigate the tectonic condition in the area. The objective of this study is to map faults and any fractures that might be acting as river channels which river Ngosur is passing through in the underground to recharge Kabatini aquifer. It has never been proved that the river channel passes underground to recharge Kabatini and Baharini aquifer to the south of the study area. The geological condition in the Kabatini area is complex and intricately related to the nature of the groundwater regime, a fact that could be attributed to the difficulty to fully assess the aquifer with the conventional hydrogeological methods alone. The entire area is covered by volcano-sedimentary materials, intercalated lava flows.

Groundwater becomes the readily available option for exploitation in areas where surface water shortages exist like the Nakuru basin. However, the over-exploitation of this resource has moved groundwater research to the forefront of the geosciences in trying to answer the questions of groundwater recharge and discharge in aquifers. These questions become increasingly relevant as we continue to test the limits of groundwater resource sustainability in areas of complex geology like Kabatini area. Whereas other researchers have worked in the area, none of them has addressed the existence or non - existence of the buried river channels and other shallow underground structures that may be controlling groundwater flow systems. The structures such as faults may form channels through which water flow and recharge the aquifer. 


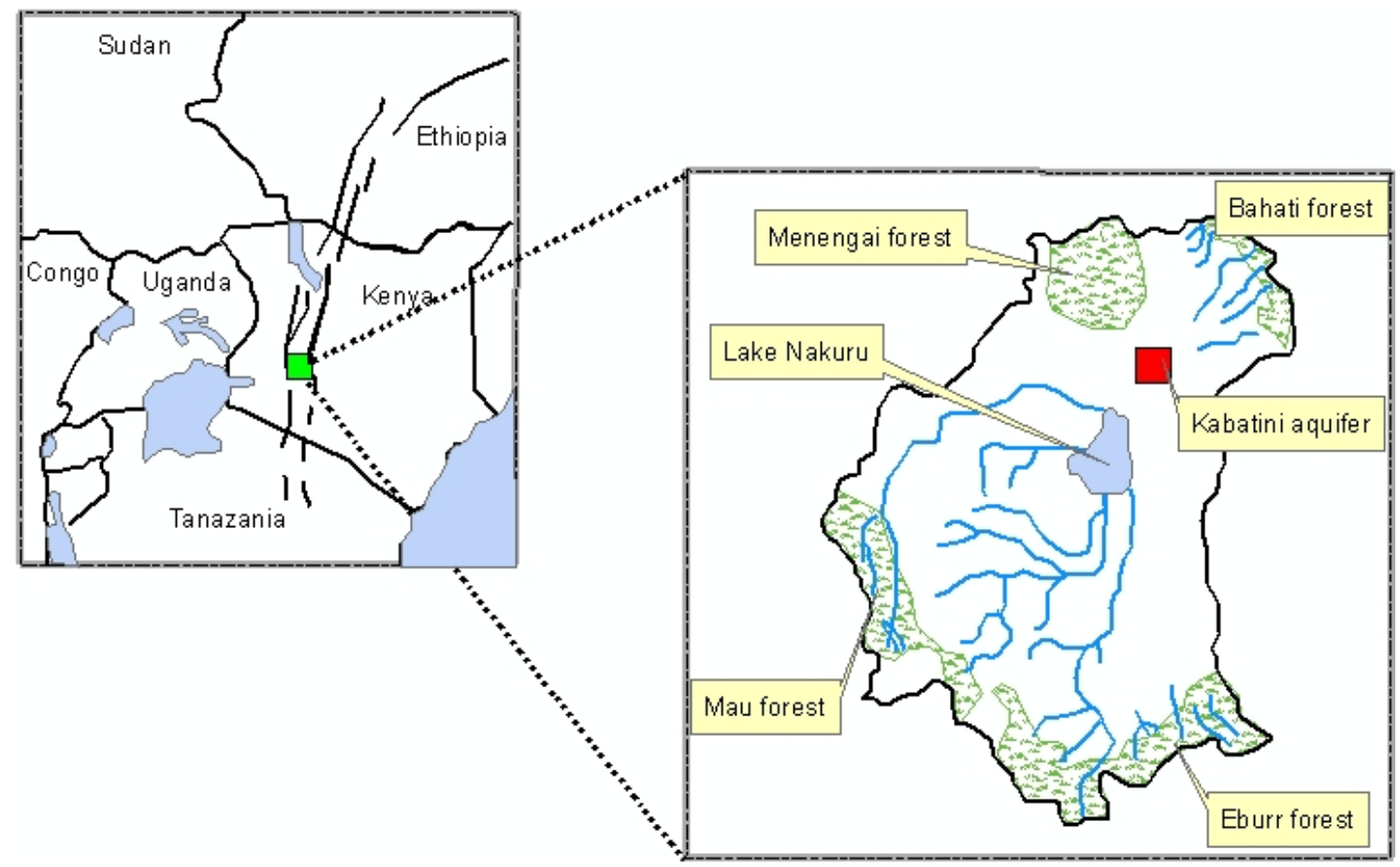

Figure 1. Location map of Kabatini aquifer north - eastern part of Nakuru town.

The study area lies in Nakuru district of rift valley province in the Republic of Kenya (Figure 1). It is covered by Nakuru topographical map sheet $119 / 3$ of scale 1:50,000. Kabatini aquifer can be located by coordinates $9971210 / 180758$ on the sheet $119 / 3$ of Nakuru. It is located on the north eastern part of Nakuru town. Nakuru town can be accessed by a tarmac road and a railway line which forms part Trans Africa railway and road network from Nairobi. Nakuru - Solai tarmac road passes on the western part of the project area. A good earth road connects to Nakuru - Solai road to the project area

Kabatini has complex geological structures which have been subjected to several tectonic processes leading to the formation of varying structural features [1]. To northern side occurs Menengai crater while to Bahati uplands occurs on the eastern part. The area is mainly occupied by volcanic rocks which consist of vitric pumice tuff, ashes, agglomerates and trachytes. The lake beds on the southern part of the area are composed mainly of volcanic material and subsequently deposited pyroclastics. The sediments are composed of sand, pebbles as well as gravels made up of rounded pumice.

\section{Methods and Their Basic Principles}

Geophysical mapping in the area consisted of Vertical Electrical Sounding (VES) method discussed in [2]. The fundamental physical law used in resistivity surveys is Ohm's law that governs the flow of current in the ground. The equation for Ohm's Law in vector form for current flow in a continuous medium is given by

$$
J=\sigma \mathrm{E}
$$

Where $\sigma$ is the conductivity of the medium, $\mathrm{J}$ is the current density and $\mathrm{E}$ is the electric field intensity. In practice, what is measured is the electric field potential. We note that in geophysical surveys, the medium resistivity $\rho$, which is equals to the reciprocal of the conductivity $(\rho=1 / \sigma)$, is more commonly used. The relationship between the electric potential and the field intensity is given by

$$
E=-\nabla \phi
$$

Combining equations (1.0) and (1.1), we get

$$
\mathrm{J}=-\sigma \nabla \phi
$$

In almost all surveys, the current sources are in the form of point sources. In this case, over an elemental volume $\Delta \mathrm{V}$ surrounding the current source I, located at (xs,ys,zs) the relationship between the current density and the current [3] is given by;

$$
\nabla . J=\left(\frac{\mathrm{I}}{\nabla \mathrm{V}}\right) \delta(\mathrm{x}-\mathrm{xs}) \delta(\mathrm{y}-\mathrm{ys}) \delta(\mathrm{z}-\mathrm{zs})
$$

Where $\delta$ is the Dirac delta function, Equation (3) can then be written as

$$
\begin{gathered}
-\nabla \cdot[\sigma(x, y, z) \nabla \Phi(x, y, z)]= \\
\left(\frac{\mathrm{I}}{\nabla \mathrm{V}}\right) \delta(\mathrm{x}-\mathrm{xs}) \delta(\mathrm{y}-\mathrm{ys}) \delta(\mathrm{z}-\mathrm{zs})
\end{gathered}
$$

Equation 1.4 is the basic equation that gives the potential distribution in the ground due to a point current source. A large number of techniques have been developed to solve this equation. This is the "forward" modeling problem that determines the potential that would be observed over a 
given subsurface structure. Fully analytical methods have been used for simple cases, such as a sphere in a homogenous medium or a vertical fault between two areas each with a constant resistivity. For an arbitrary resistivity distribution, numerical techniques are more commonly used (Koefoed [4]; Dey and Morrison [5]).

We consider the simplest case of a homogeneous subsurface and a single point current source on the ground surface. In this case, the current flows radially away from the source, and the potential varies inversely with distance from the current source (Keller and Frischknecht [6]; Daniel and Alberty [7]; Telford [8]). The equipotential surfaces have a hemisphere shape, and the current flow is perpendicular to the equipotential surface. The potential in this case is given by

$$
\Phi=\frac{\rho \mathrm{I}}{2 \pi r}
$$

where $r$ is the distance of a point in the medium (including the ground surface) from the electrode. In practice, all resistivity surveys use at least two current electrodes, a positive current and a negative current source. The potential values have a symmetrical pattern about the vertical place at the mid-point between the two electrodes. The potential value in the medium from such a pair is given by:

$$
\Phi=\rho \mathrm{I} / 2 \pi\left(\frac{1}{\mathrm{rc}_{1}}-\frac{1}{\mathrm{rc}_{2}}\right)
$$

where $\mathrm{rc}_{1}$ and $\mathrm{rc}_{2}$ are distances of the point from the first and second current electrodes.

The potential difference between two points (normally on the ground surface) is measured. The potential difference is then given by;

$$
\Delta \Phi=\frac{\rho}{2 \pi}\left(\frac{1}{r c_{1} p_{1}}-\frac{1}{r c_{2} p_{1}}-\frac{1}{r c_{1} p_{2}}+\frac{1}{r c_{2} p_{2}}\right)
$$

The above equation gives the potential that would be measured over a homogenous half space with a 4 electrodes array. Actual field surveys are invariably conducted over an inhomogeneous medium where the subsurface resistivity has a $3-\mathrm{D}$ distribution. From the current (I) and potential ( $\Delta \Phi)$ values, an apparent resistivity $(\rho \mathfrak{a})$ value is calculated.

$$
\rho \mathfrak{a}=\mathrm{k} \frac{\Delta \phi}{\mathrm{I}}
$$

where

$$
\mathrm{k}=\frac{2 \pi}{\left(\frac{1}{r c_{1} p_{1}}-\frac{1}{r c_{2} p_{1}}-\frac{1}{r c_{1} p_{2}}+\frac{1}{r c_{2} p_{2}}\right)}
$$

$\mathrm{k}$ is a geometric factor that depends on the arrangement of the four electrodes. Resistivity measuring instruments normally give a resistance value $R=\Delta \phi / \mathrm{I}$, so in practice the apparent resistivity value is calculated by:

$$
\rho \mathfrak{a}=k R
$$

The calculated resistivity value is not the true resistivity of the subsurface, but an "apparent" value that is the resistivity of a homogeneous ground that will give the same resistance value for the same electrode arrangement.

Resistivity is a fundamental electrical property of rocks, which is closely related to rock lithology of which the main controlling factors are bulk rock porosity, pore structure, amount and salinity of water, temperature and the presence of clays (Griffiths [9]). To convert the resistivity picture into a geological one requires some knowledge of the typical resistivity values for the different types of subsurface materials and geology of the surveyed area. Groundwater quality analysis information on boreholes indicate the mean electrical conductivity (EC) of the waters is approximately to $550 \mu \mathrm{S} / \mathrm{cm}$ and therefore its mean resistivity $(\rho)$, the reciprocal of EC is 18.181 Ohm.m. Empirical studies have demonstrated that a correlation exists between $\mathrm{F}$ (formation factor) and the particle size of sedimentary materials (Sporry [10]). The formation factor (F) were calculated for the station 0 ,E near the boreholes along profile A-B where vertical resistivity sounding surveys was carried out using the following formula.

$$
\mathrm{F}=\frac{\rho_{f}}{\rho_{w}}
$$

where $\rho_{f}$ is the resistivity of formation, and $\rho_{w}$ is the resistivity of pore water. This relation is a derivation from Archie's Law (Keller and Frischknecht [6]).

Vertical distribution of resistivities within a particular volume of earth is known as geoelectrical section. The sub-surface data can often be approximately determined by a geoelectrical section using Vertical electrical sounding (VES) which is demonstrated in Figure 2. In figure 2A, two dimensional sections E1, E2 ....... En-1 are the thickness. $\mathrm{Z} 1=\mathrm{E} 1, \mathrm{Z} 2=\mathrm{E} 1+\mathrm{E} 2 \ldots \mathrm{Zn}-1=\mathrm{E} 1+\ldots . .+\mathrm{En}-1$ is the depth of the bottom of successive layers and are the true resistivities of the respective layers. The last $n$th layer is taken to have a great thickness i.e. En $=\infty$. Geoelectrical sections can be classified depending on the number of layers $n$. For two layers $n=2$ : three layers, $n=3$ : four layers, $\mathrm{n}=4$ and so on. Each category is classified according to the pattern of resistivity variation with depth. Two types of two layer sections are possible i.e., $\mathrm{P} 1>\mathrm{P} 2$ and $\mathrm{P} 1<\mathrm{P} 2$ as shown in the figure $2 \mathrm{~B}$. Three layers sections has four possibilities (Figure 2B); (a) Type H: P1 $>\mathrm{P} 2>\mathrm{P} 3$ (b) Type K: $\mathrm{P} 1<\mathrm{P} 2>\mathrm{P} 3$ (c) Type A: $\mathrm{P} 1<\mathrm{P} 2<\mathrm{P} 3$ and (d) Type Q: $\mathrm{P} 1>\mathrm{P} 2>\mathrm{P} 3$. There are eight possibilities for four layers sections (Figure $2 \mathrm{C}-\mathrm{G}$ ). The section may be identified by combination of three layer designation as AA will correspond to $\mathrm{P} 1<\mathrm{P} 2<\mathrm{P} 3<\mathrm{P} 4$. Similarly $\mathrm{HK}$ will correspond to $\mathrm{P} 1>\mathrm{P} 2<\mathrm{P} 3>\mathrm{P} 4$. In the present studies the type sections encountered as $\mathrm{H}$ and $\mathrm{K}$ type. In Most cases, the electrode separation is 100 meters only. It cannot penetrate greater depth. 

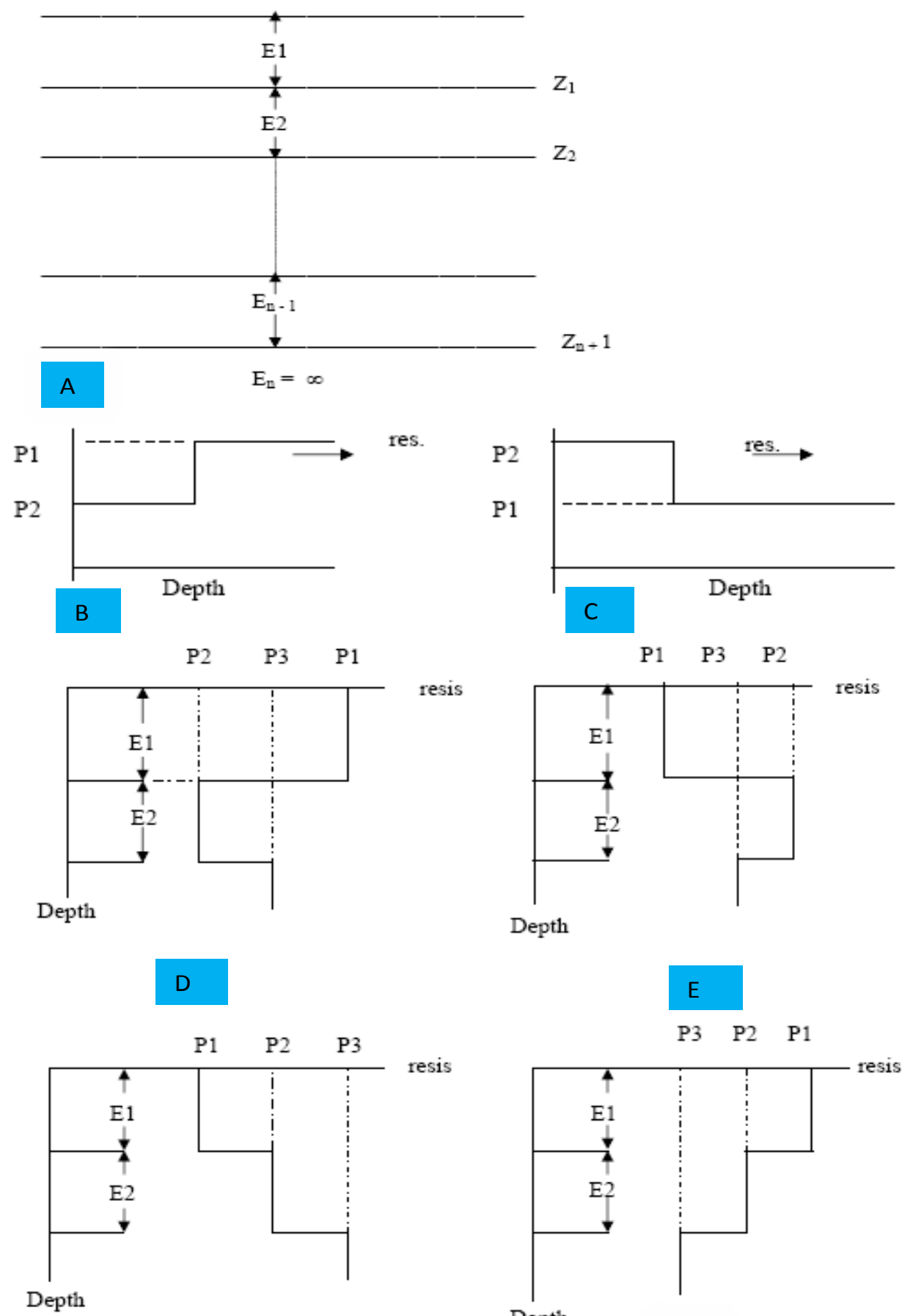

F

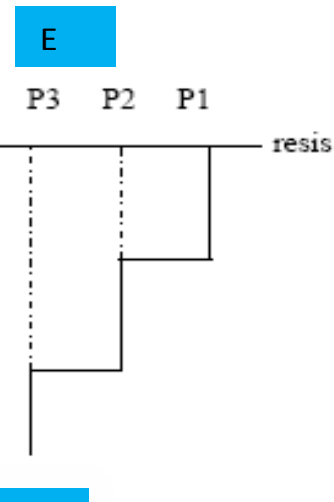

Figure 2. (A) Two dimensional sections thickness of layers that may be experienced in schlumberger's array. (B)Two layer section in schlumberger's configuration. (C-G)Three layer sections in Schlumberger's configuration.

\subsection{Field Method}

The aim of geological interpretation of resistivity sounding data is to determine the thickness and resistivity of different horizons from a study of the Vertical Electrical Sounding (VES) field curves and to use these results to obtain a complete geological picture of the area under investigation. The Vertical Electrical Sounding data obtained in this work was analyzed by using the method in Zohdy [11] and computer based inversion using EarthImager software, which allows the performance of automatic interpretation of the Schlumberger sounding curves to obtain the equivalent n-layer model from the apparent resistivity curve of each sounding. This procedure was used for all the sounding points obtained in the study area, in order to obtain the equivalent apparent resistivity 
models of each sounding, their depths as well as thicknesses. Different curve types were identified in the area showing different geo-electric layers. These layers are of different shapes and characteristics which is typified by the formation. The numerous layers that were generated by the computer were grouped into relevant geologic depth intervals called geo-electric sections and the resulting layer parameters were then given geologic interpretation. The type of curves, the resistivity of the sediments and the lithological logs from nearby boreholes were used in conjunction with the knowledge of the local geology of the study as guides in the interpretation and analysis of the geologic section in terms of shallow structures and buried river channels. The knowledge of the local geology of Kabatini was used in constructing the earth model. The lithology indicates broadly that within the depth penetrated; the succession is clay, clay silt, and fine to medium sand, coarse sand, pebbles, boulders, tuffs and lava [12].

A total of 16 vertical electrical soundings were carried out using Schlumbeger electrode configuration. Four profiles A- D, E- H, I - L and M - P were aligned in the East - West direction (Figure 3). Each profile was separated from the adjacent profile by an interval of 50 meters. Sounding stations along the profile were 100 meters apart. The direction of the profiles was selected depending on how open the terrain was to allow for a wider $A B / 2$ electrode spread. East to west direction was found to be appropriate since it perpendicular to the principal structures in the area. Geology, elevation and ground conditions were noted at and around each station down before spreading the cables and fixing the electrodes in the ground. The electrode position was fixed using a GPS on a straight line. The equipment was placed midway between the current and potential electrodes. The potential electrodes were connected to terminals $\mathrm{M}$ and $\mathrm{N}$ on the equipment. The current electrodes were also connected to terminals $\mathrm{A}$ and $\mathrm{B}$ of the equipment. Steel current and potential electrodes were then hammered into the ground. The machine was switched on to read the readings and readings were recorded on prepared data sheets.

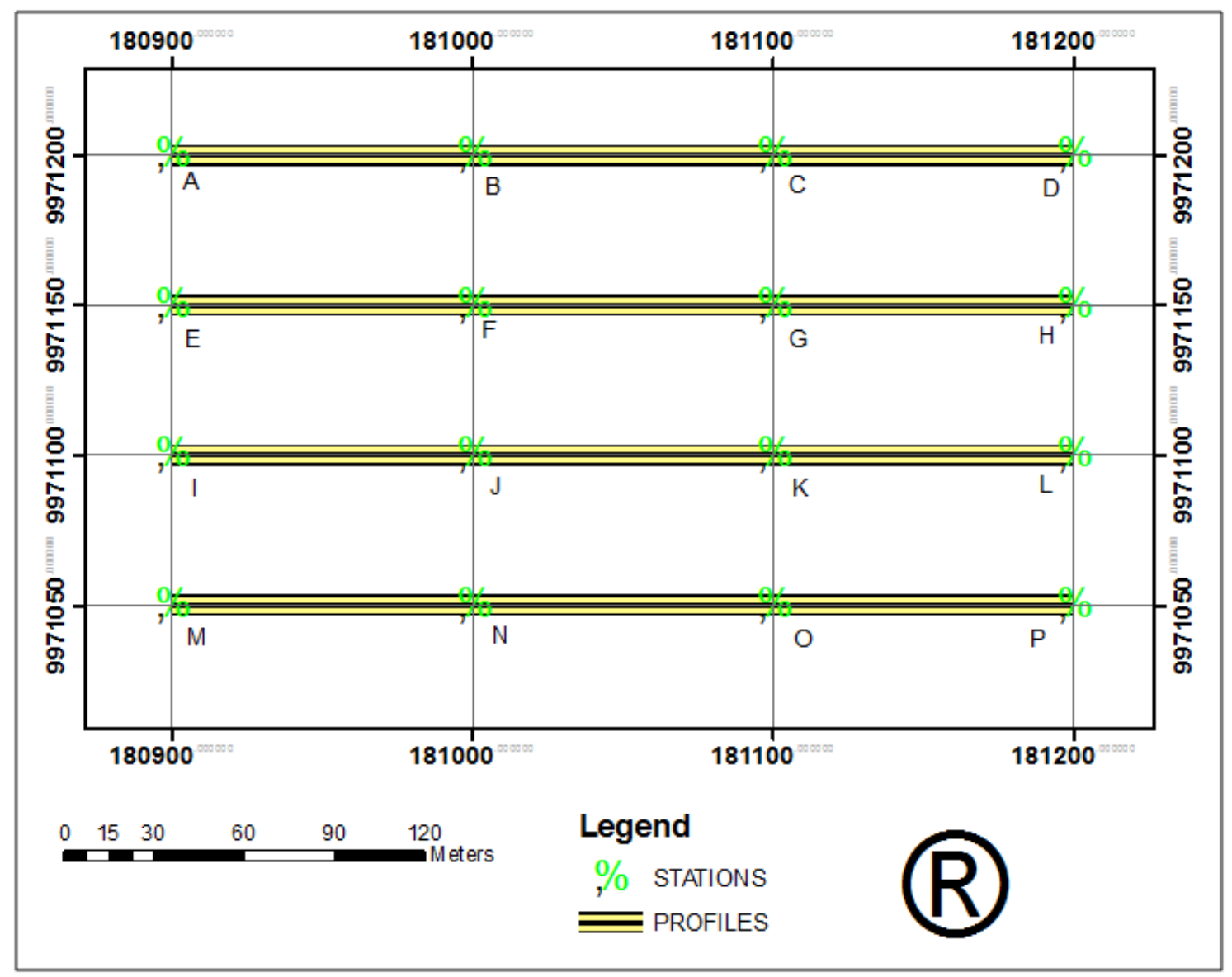

Figure 3. Map showing VES (Vertical electrical sounding) profiles in Kabatini aquifer. 


\section{Interpretation of the Results}

\subsection{Analysis and Interpretation of VES Stations on Profile A - D}

Profile A $-\mathrm{D}$ is located on the northern part (latitude 9971200) of the study area and consists of stations A, B, C and D.

\section{Station A}

The curve shows a typical trend of $\mathrm{K}-\mathrm{H}-\mathrm{K}$. Layers 1-3 have moderate resistivity values between 56.369 and $87.823 \mathrm{ohm}$ meter. There is an ascending trend in the resistivity values from the surface to layer 5 . The resistivity values then decline abruptly from 145.373 on layer five to 76.099 and 45.05 of layers 6 and 7 respectively. Layer 8 and 9 shows an increase in the resistivity values which declines again on layers 10,11 and 12. The curve indicates two conductive layers, of which one is confined between layers 5 and 8 . The other conductive layer begins from layer 10 to the layer 12(Figure $4 \mathrm{~A}$ ). The thickness of layer 12 cannot be determined because it occurs at the bottom.

\section{Station B}

The first layer of station B consist of very low resistivity material which could be clay saturated with water. Resistivity values for layers 2,3,4 and 5 are 20.1,44.3,215.1 and $657.5 \mathrm{ohm}$ meter respectively. There is an ascenting trend of the curve for this layers. The values of layers $6,7,8$, and 9 show descenting trend of the resitivity values indicating the shallow strucutres containing low resistivity at a depth of $15 \mathrm{~m}$. The inversion curves of $\mathrm{K}-\mathrm{H}-\mathrm{K}$ is observed in this station (Figure $4 \mathrm{~B}$ ). Layers 1, 2 and 3 have moderate resistivity values that indicate the presence of conductive materials (Figure $4 \mathrm{~B}$ ). Resistivity values increases abruptly in layer 4,5 and 6 indicating the presence of nonconductive material probably the boulder of Phonolite material. The resistivity values of layer 7 and 8 are low indicating the existence of conductive material in these two layers. Layers (more than 11.5 meters) showing the indication of shallow confined aquifer. The ninth and tenth layer indicates high to very resistivity respectively showing the presence of non-conductive material in layer 10. The values of resistivity declines in layer 11 from 78 ohm meter to $30 \mathrm{ohm}$ meter showing the presence of conductive body that goes deeper into the earth.

\section{Station C}

The resistivity of the first two thin layers from the surface are low. The values of resistivity rise abruptly in the second and third layers to 120 and $237.341 \mathrm{ohm}$ meter respectively and begin to decline on the fifth layer and sixth layer as a result of highly conductive material. This sixth layer is underlain by high resistivity material in the seventh and eighth layers. Drastic decline in resistivity values is observed in the eleventh and twelfth layer at the bottom. The curve of this station consists of K-H-K type (Figure $4 \mathrm{C}$ ).

\section{Station D}

This station occurs to the east of the station $\mathrm{D}$ on profile A - D. The first five layers from the surface are thin layers whose resistivity values vary from very low to moderately low. Resistivity value of layer one is 57.72 ohm meter indicating that this is a clay silty formation which is relatively dry. Layers 2, 3 and 4 have very low resistivity values which indicate the existence of a highly conductive material. Layer 6 which has the thickness of $3.598 \mathrm{~m}$ has moderate resistivity value that is higher than the underlying layer number 7 . Low resistivity value of layer 7 shows that it has a good conductive material probably water saturated body forming the first upper aquifer. The eighth and ninth layers have high resistivity values indicating that these layers are probably Phonolite or have basaltic material. There is a declining trend of the resistivity values from layer 10 to the bottom layer showing the occurrence of very highly conductive material probably a second type of an aquifer that is semi confined. The curve displayed shows $\mathrm{K}$ -H curve pattern whereby an upper layer having high resistivity values overlies a lower layer with lower resistivity values (Figure $4 \mathrm{D}$ ). This layer overlies a layer of higher resistivity values which is underlain by a layer with low resistivity values. 
PROFILE A - D

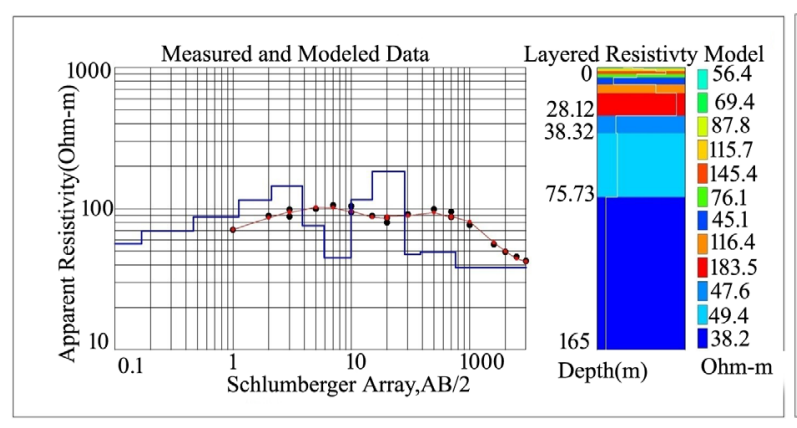

A

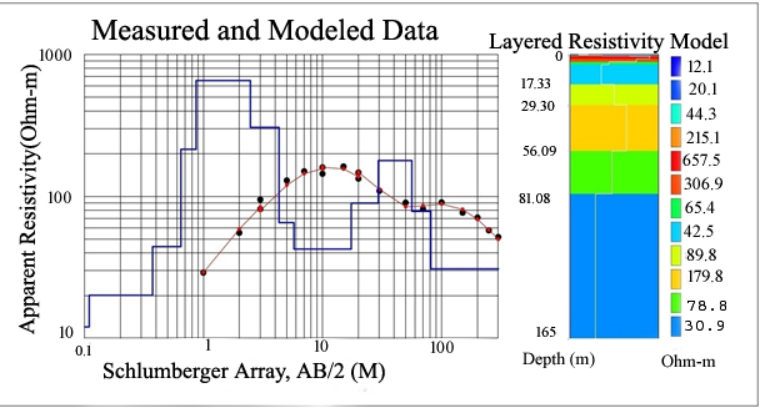

B

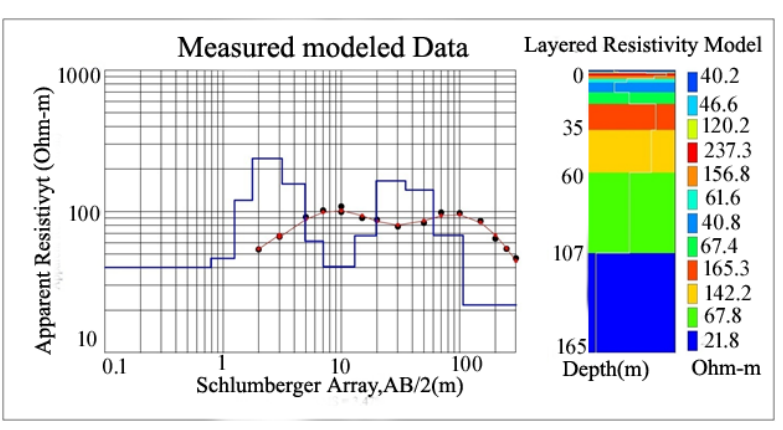

C

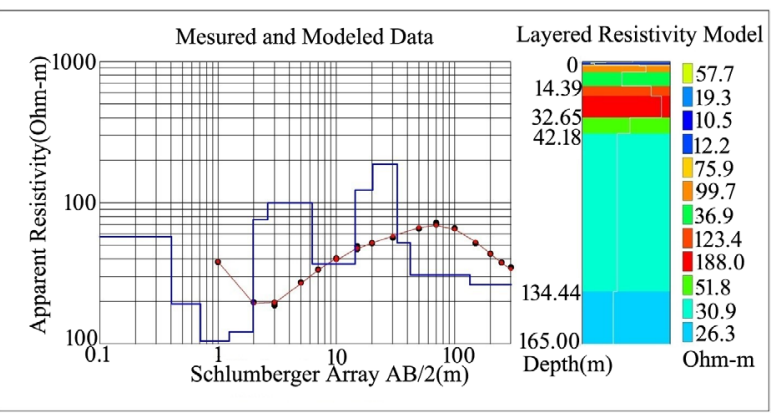

D

\section{PROFILE E - H}

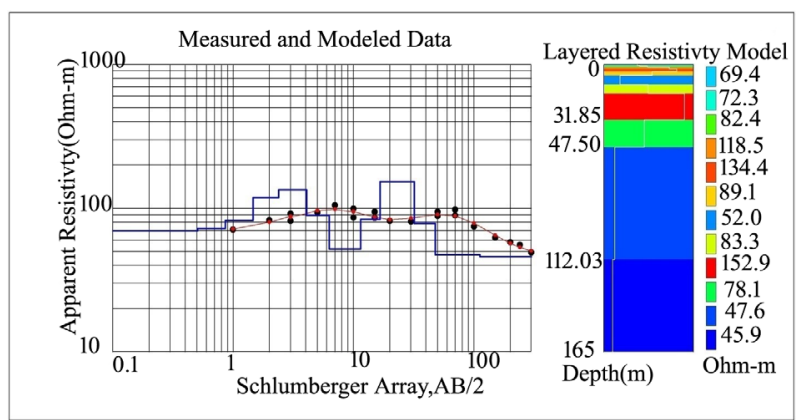

E

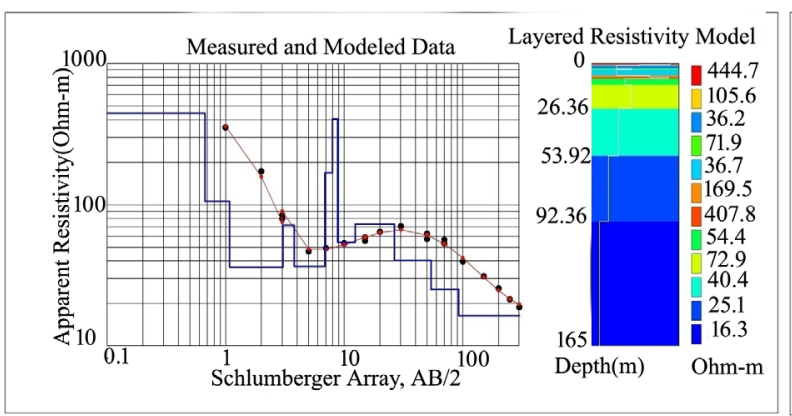

G

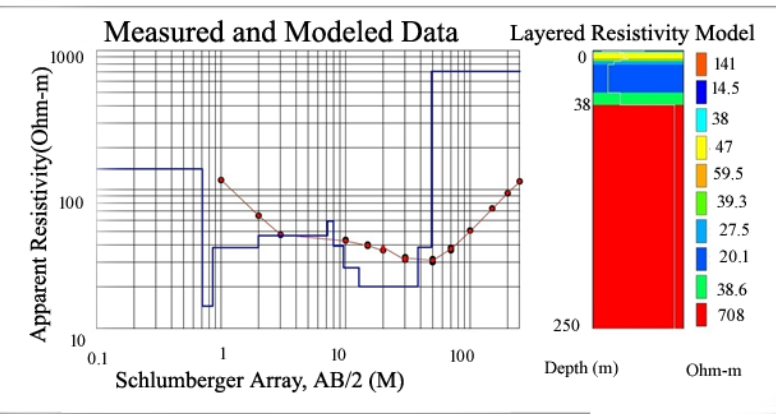

F

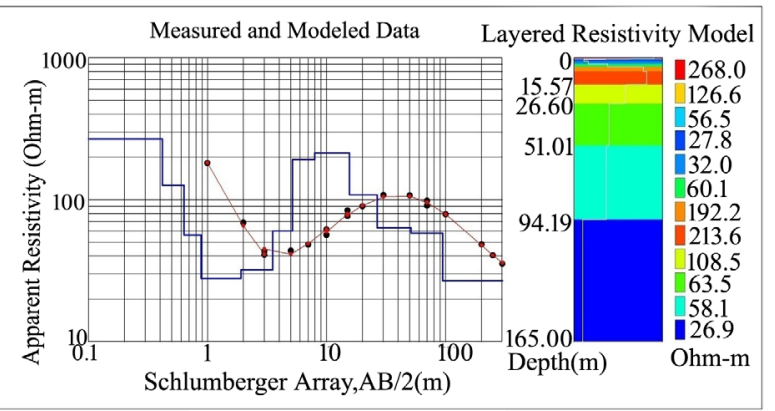

$\mathrm{H}$

Figure 4. Layered resistivity models for stations A, B, C, D, E, F, G, and H. 


\subsection{Analysis and Interpretation of VES Stations on Profile $\mathbf{E}-\mathbf{H}$}

This profile occurs to the south of profile $\mathrm{A}-\mathrm{D}$ along latitude 991150. The profile runs in the east to west direction and contains VES stations E, F, G and H.

\section{Station E}

The curve obtained in this station displays $\mathrm{K}-\mathrm{H}-\mathrm{K}$ pattern (Figure $4 \mathrm{E}$ ). This indicates that the top most layers has lower resistivity values which increases up to the sixth layer and then declines on the seventh layer indicating the existence of high conductive material in a shallow structure. The resistivity values increases again in the ninth layer to 152.864, but declines in the subsequent layers indicating another deeper structure containing conductive material up to the depth greater than $165 \mathrm{~m}$.

\section{Station F}

The type of the curve observed in this station is a combination of Q - H - A (Figure $4 \mathrm{~F}$ ) indicating very high resistivity values on the bottom layer. The first layer on the top has high resistivity value of $140.88 \mathrm{ohm}$ meter. The resistivity values drops abruptly to $14.542 \mathrm{ohm}$ meter in the second layer. The resistivity values increases slowly on the third, fourth and fifth layer and then begins dropping again on the sixth, seventh and eighth layer. The eighth layer whose thickness is $25.15 \mathrm{~m}$ thick has a low resistivity value of $20.05 \mathrm{ohm}$ meter signifying the existence of conductive material which is a confined aquifer in shallow structure. Resistivity values begin to increase on the ninth layer reaching a maximum of $708.9 \mathrm{ohm}$ meter on the tenth layer. The tenth layer has a thickness that is greater than $210 \mathrm{~m}$ which indicates that this layer could be part of an intrusion within the study area.

\section{Station G}

This station is found on the second profile $\mathrm{C}-\mathrm{D}$, which occurs to the south of profile A-B. The first layer has very high resistivity values (444.7 Ohm meter) indicating the presence of unweathered Phonolite, the values of resistivity drops significantly in the second and third layers. The third layer is underlain by a relatively high resistivity value layer which overlies a fifth low resistivity value layer at a depth of 3.77 to $6.844 \mathrm{~m}$. The resistivity values for the sixth and seventh layer increases abruptly but declines on the subsequent layers till it reaches very low resistivity value of $16.33 \mathrm{ohm}$ meter on the bottom layer. The Q -H-Q type curve is noted in this station (Figure $4 \mathrm{G}$ ).

\section{Station H}

The first four layers show a decline in resistivity values. Resistivity values begin to rise on the fifth layer up to the eighth layer. The values for the underlying layers show a decline up to the bottom layer which has $26.85 \mathrm{ohm}$ meters.
The curve shows an $\mathrm{H}$ - K. trend (Figure $4 \mathrm{H}$ )

\subsection{Analysis and Interpretation of VES Stations on Profile I - L}

This profile occurs to the south of profile $\mathrm{C}-\mathrm{D}$ along latitude 9971100. The profile runs in the east to west direction and contains VES stations I, J, K, and L

\section{Station I}

This station has a resistivity of $131.433 \mathrm{ohm}$ meter on the upper layer which increases to a maximum of 433.42 ohm meter in third layer. The resistivity values then decline steadily up to $63.73 \mathrm{ohm}$ meter on the ninth layer. The ninth layer has a thickness of $23.346 \mathrm{~m}$ thick with moderate resistivity because of having relatively high conductive material at a depth of $45.49 \mathrm{~m}$ from the surface. The resistivity values of the tenth layer increases to 118.937 ohm meter, but the drops gradually on the eleventh layer. Bottom layer has got very low resistivity as compared with the resistivity of the layers above it. The curve obtained in this station is a $\mathrm{K}-\mathrm{Q}$ curve (Figure $5 \mathrm{I}$ )

\section{Station J}

The first layer of this station has moderate resistivity which increases gradually up to the fifth layer which has resistivity values of $141.208 \mathrm{ohm}$ meter. Layers seven and eight have moderate resistivity of 72.024 and $73.539 \mathrm{ohm}$ meter respectively. There is a rising trend of the resistivity values in the ninth to twelfth layer forming $\mathrm{K}-\mathrm{A}$ (Figure 5 J). The high resistivity of $1197.9 \mathrm{ohm}$ meter of the bottom layer indicates the existence of an intrusive material that whose thickness cannot be determined because it is the bottom layer.

\section{Station K}

The first layer in this station has a very low resistivity value which increases in the second layer. The resistivity of the third layer indicates clay material overlying the fifth layer that has moderate resistivity of $84.426 \mathrm{ohm}$ meter. The low resistivity values of the sixth and seventh layer increase to the peak of $169.027 \mathrm{ohm}$ meter in the ninth layer after which the trend declines to $23.546 \mathrm{ohm}$ meter on the twelfth layer. The type of the curve formed in this station is $\mathrm{K}$ curve (Figure $5 \mathrm{~K}$ )

\section{Station L}

The first layer shows moderate resistivity value of $71.483 \mathrm{ohm}$ meter which declines up to $34.657 \mathrm{ohm}$ meter in the fourth layer. The trend of the resistivity values rises from the fifth layer to the ninth layer. Resistivity values drops gradually from the tenth layer up to $22.119 \mathrm{ohm}$ meter in the twelfth layer. The type of the curve obtained in the station is the H-K curve (Figure $5 \mathrm{~L}$ ). 
PROFILE I - L

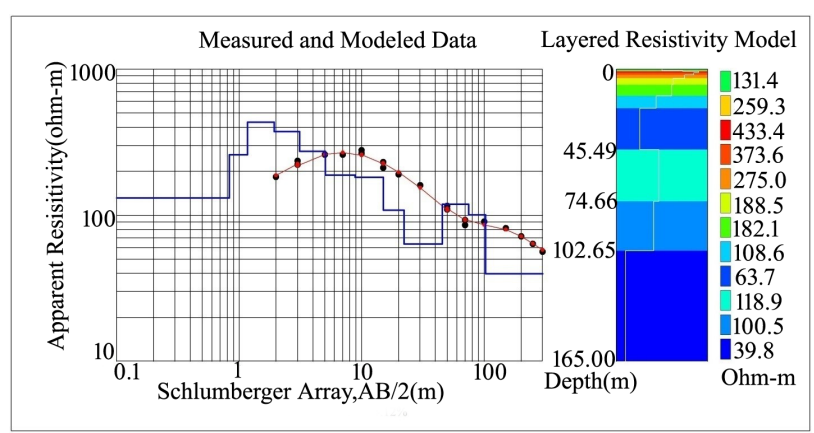

।

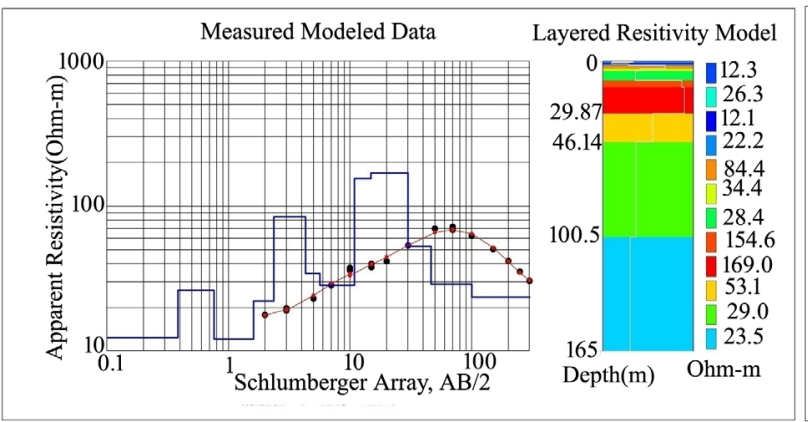

K

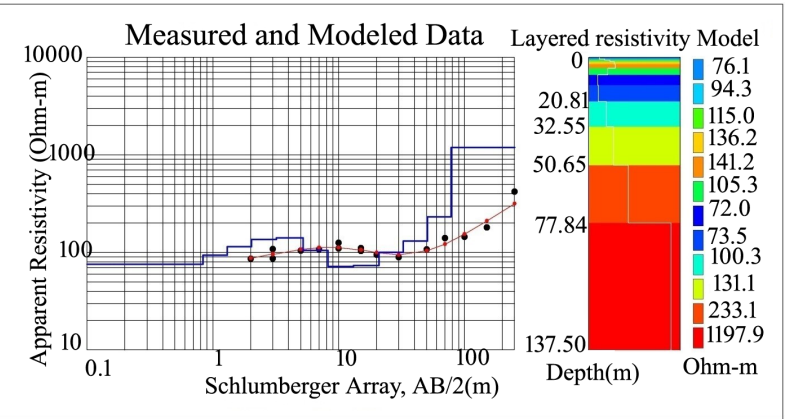

J

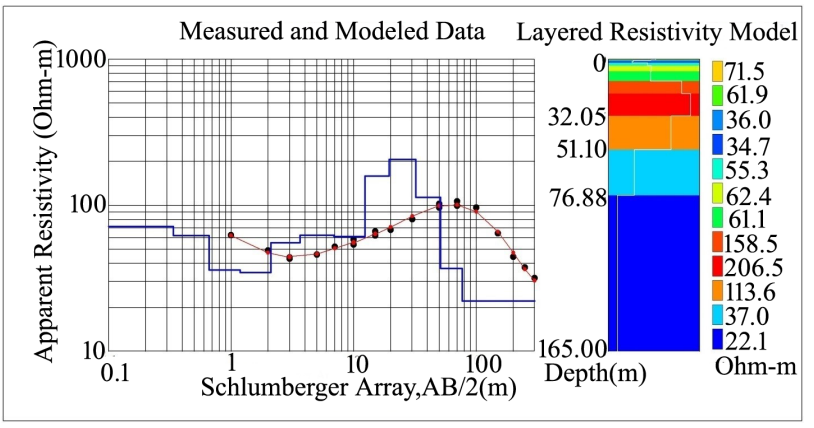

$\mathrm{L}$

PROFILE M - P

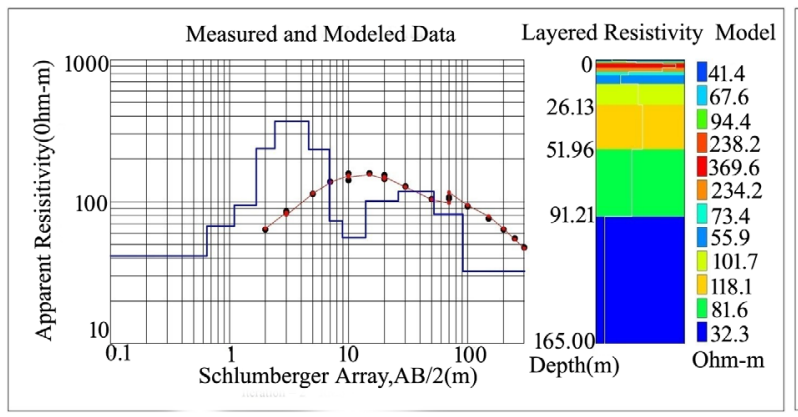

M

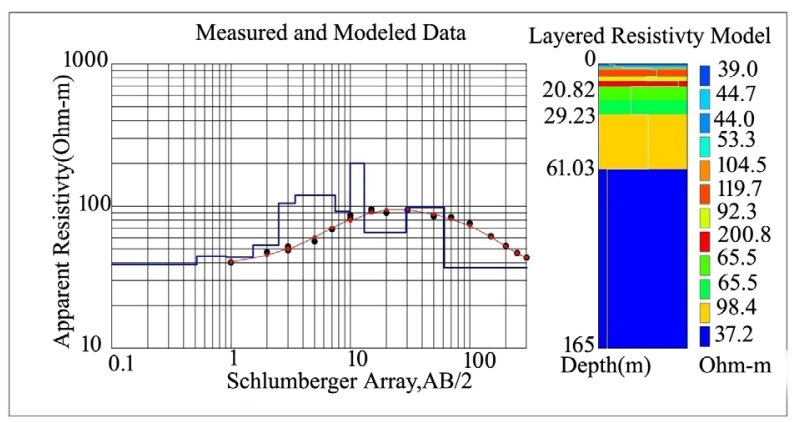

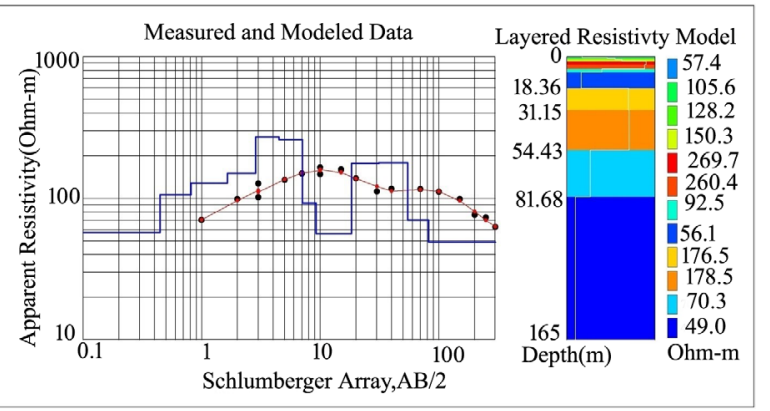

$\mathrm{N}$

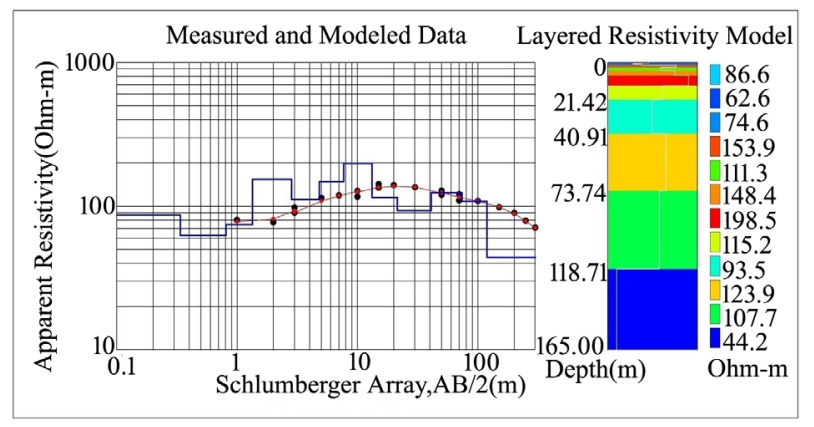

Figure 5. Layered resistivity models for stations I, J, K, L, M, N, O, and P 


\subsection{Analysis and Interpretation of VES Stations on Profile M - P}

This profile occurs to the south of profile E - F along latitude 9971050. The profile runs in the east to west direction and contains VES stations $\mathrm{M}, \mathrm{N}, \mathrm{O}$, and $\mathrm{P}$.

\section{Station M}

The first layer of this station has low resistivity value of $41.42 \mathrm{ohm}$ meter. The trend of resistivity increases up to $369.573 \mathrm{ohm}$ meter in the fifth layer. The resistivity values then decreases from the sixth layer which has $234.194 \mathrm{ohm}$ meter to $55.874 \mathrm{ohm}$ meter in eighth layer. The values of resistivity increases again slightly to $118.101 \mathrm{ohm}$ meter after which it declines to low resistivity values of 32.293 $\mathrm{ohm}$ meter in the bottom layer. The curve of this station is in the form of $\mathrm{K}$ curve (Figure $5 \mathrm{M}$ ).

\section{Station N}

The resistivity of the first five layers from the surface increase with depth. The values of resistivity $r$ decrease from the sixth layer abruptly from $260.351 \mathrm{ohm}$ meter to 92.497 and $56.11 \mathrm{ohm}$ meter in layers seven and eight respectively. The eighth layer is underlain by high resistivity material in the ninth and tenth layers. Drastic decline in resistivity values is observed in the eleventh and twelfth layer at the bottom. The curve of this station consists of A-Q type (Figure $5 \mathrm{~N}$ ).

\section{Station O}

The first layer in this station has low resistivity value which increases in the second, third, fourth, fifth and sixth layer. The resistivity of the seventh layer is lower than the overlying and underlying layers. The low resistivity values of the seventh layer increase to the peak of $200.766 \mathrm{ohm}$ meter in the ninth layer after which the trend declines to $37.1151 \mathrm{ohm}$ meter on the twelfth layer. The type of the curve formed in this station is $\mathrm{K}$ curve (Figure $5 \mathrm{O}$ ).

\section{Station P}

The curve of this station indicate a general ascending trend corresponding to a gradual increase in the resistivity with depth up to 13 meters after which the resistivity falls gradually $44 \mathrm{ohm}$ meter in the bottom layer. The curve displayed at this station is $\mathrm{K}$ type curve (Figure $5 \mathrm{P}$ )

\subsection{Iso - resistivity maps}

\subsubsection{Vertical section Iso - resistivity map of profile A - D}

Vertical section of this profile shows that resistivity of values greater than $100 \mathrm{ohm}$ - meter occurs between $0 \mathrm{~m}-$ $80 \mathrm{~m}$ depth. Resistivity values occurring below $80 \mathrm{~m}$ have are less than a hundred which indicates the presence of high conductivity material like a mass of water (Figure 6). Very low resistance material occurring on the eastern part of the profile indicates the presence of the river channel in this location. The low resistance values extend beyond the depth of $165 \mathrm{~m}$ showing that the depth of the river channel and the aquifer of Kabatini exceeds $165 \mathrm{~m}$.

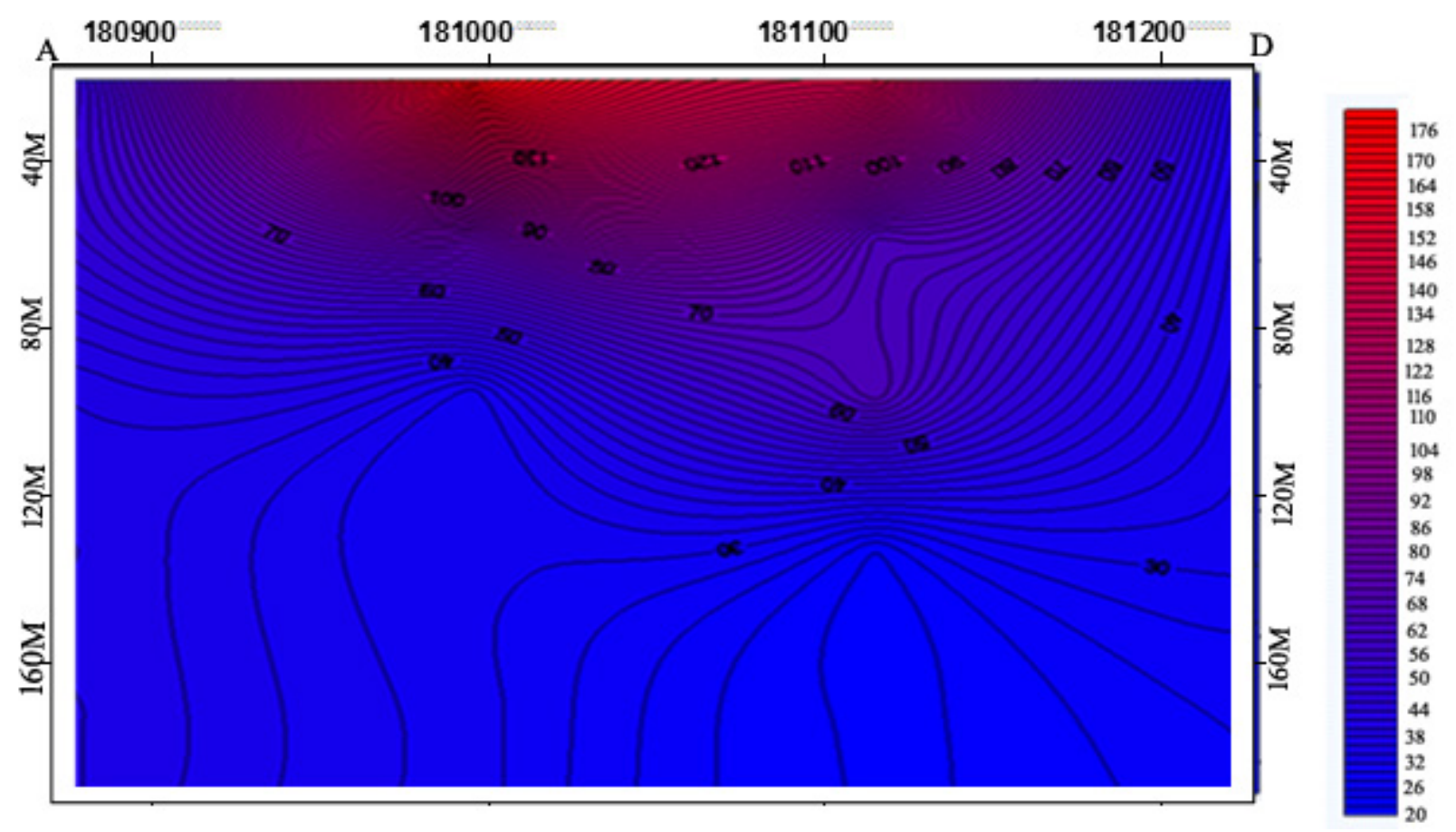

Figure 6. Vertical section for profile A - D, along latitude 9971200 (see Figure 3) 


\subsubsection{Vertical Section of Profile E-H}

The eastern part of this pseudo-section has low resistivity values (Figure 7) indicating the location of the river channel. High resistance is observed from $50 \mathrm{~m}$ to a depth greater than $165 \mathrm{~m}$ between $40 \mathrm{~m}$ to $60 \mathrm{~m}$ from C towards D on the western part of this profile. The depth of the aquifer along the profile is greater than $165 \mathrm{~m}$. The high resistance material observed along this profile could be the un-weathered Phonolite material.

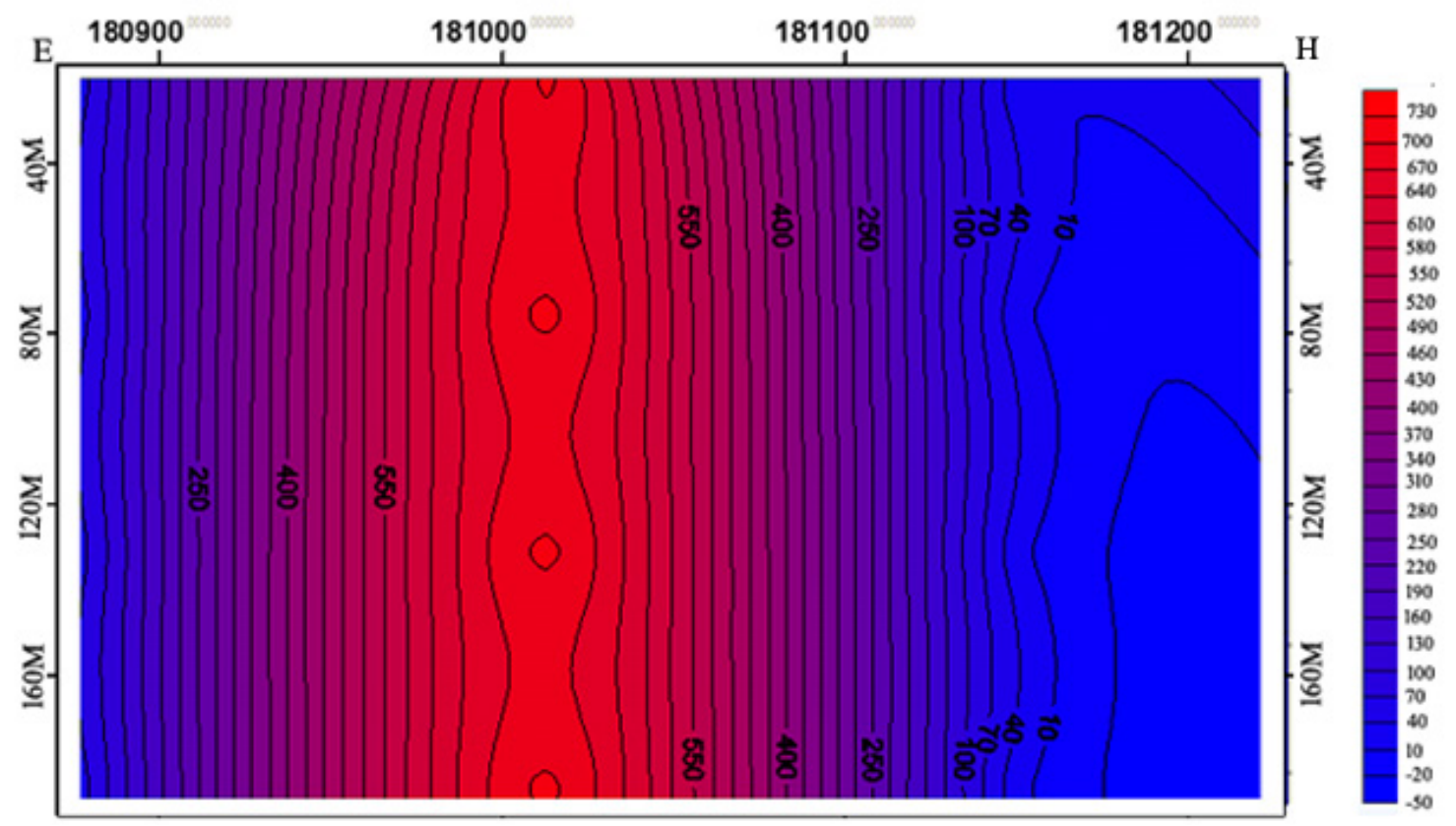

Figure 7. Vertical section for profile E - H along latitude 9971150 (see Figure 3). Low resistivity values are on the eastern part of the profile, especially at longitude 181200 .

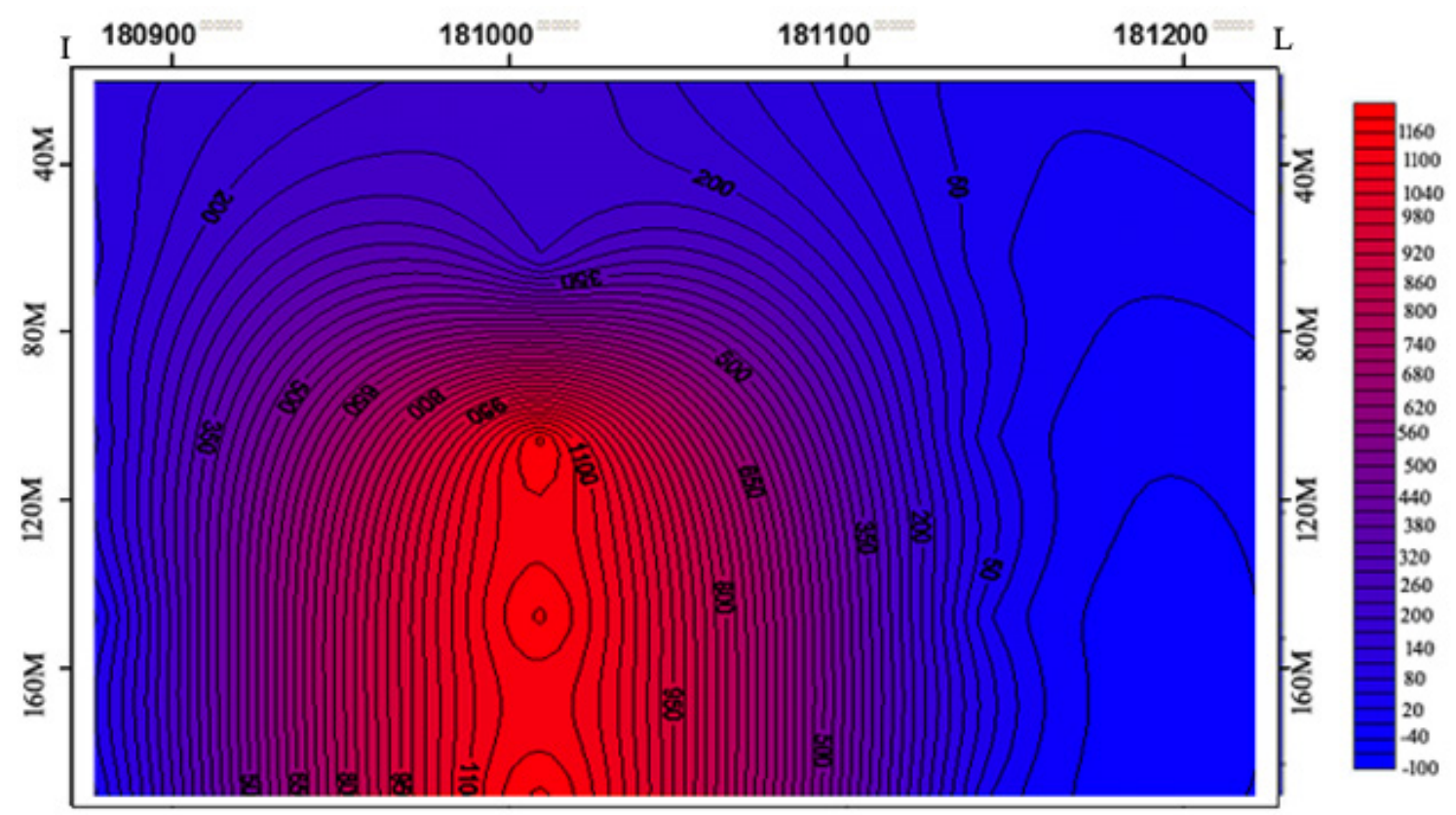

Figure 8. Vertical section for profile I - L along latitude 9971100 (as shown Figure 3). Low resistivity values are separated from high resistivity values by $50 \mathrm{ohm}-$ meter level contour. 


\subsubsection{Vertical Section of Profile I-L}

Vertical Iso - resistivity map of profile E-F shows higher conductivity material concentrating on the eastern part of VES profile while low conductive material occurring mostly on the western part of the area to the depth that is more than $165 \mathrm{~m}$ (Figure 8). The low resistance material of the eastern part of the VES profile indicates the presence of the river channel in the study area. The high resistance material on the eastern part of the profile E-F of the vertical electrical sounding pseudo-section indicates the existence of an intrusion in the study area.

\subsubsection{Vertical Section of Profile M-P}

Vertical Iso-resistivity of profile G-H shows moderate resistance material non-uniformly distributed from the surface to the depth of about $100 \mathrm{~m}$. (Figure 9). Low resistance material is also distributed non-uniformly along this profile. Very low resistance material is found to concentrate more on the eastern part of the profile G-H.

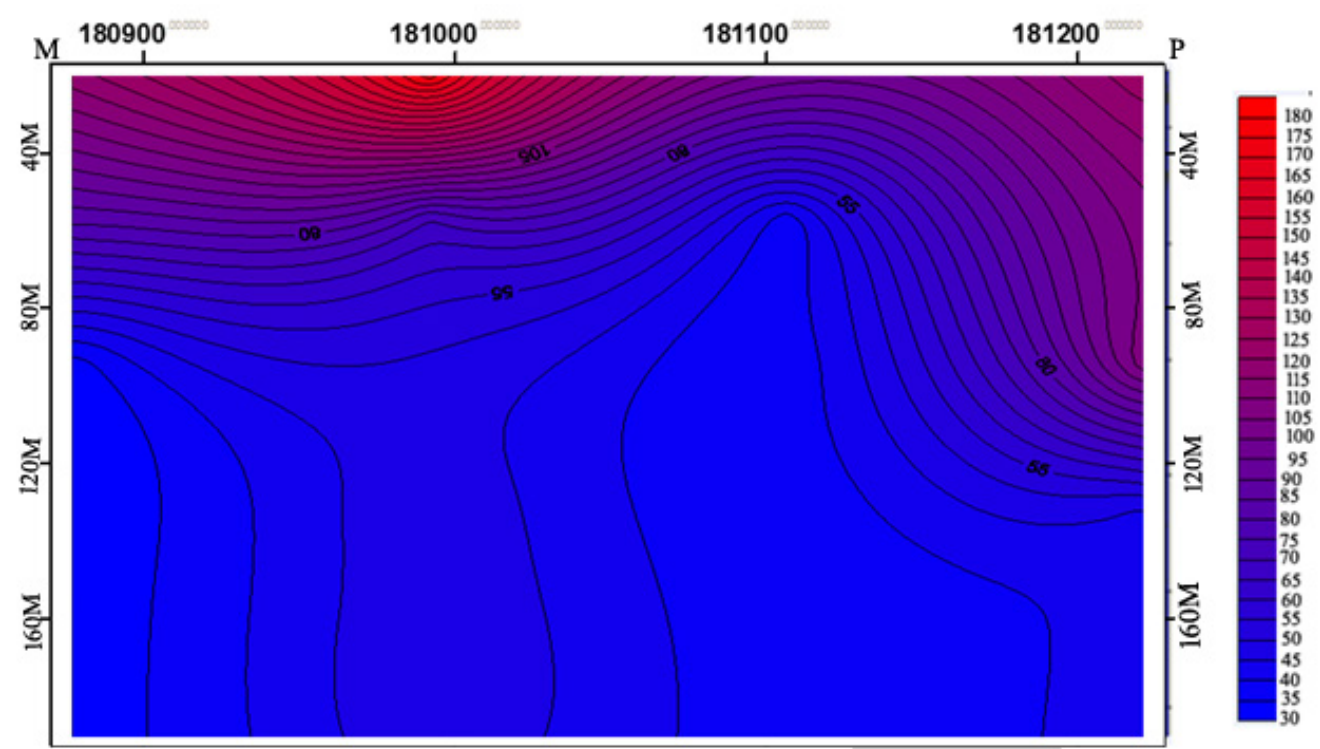

Figure 9. Vertical section for profile M - P along profile 9971050 (see Figure 3). Highly conductive material exists beyond 100m below the surface.

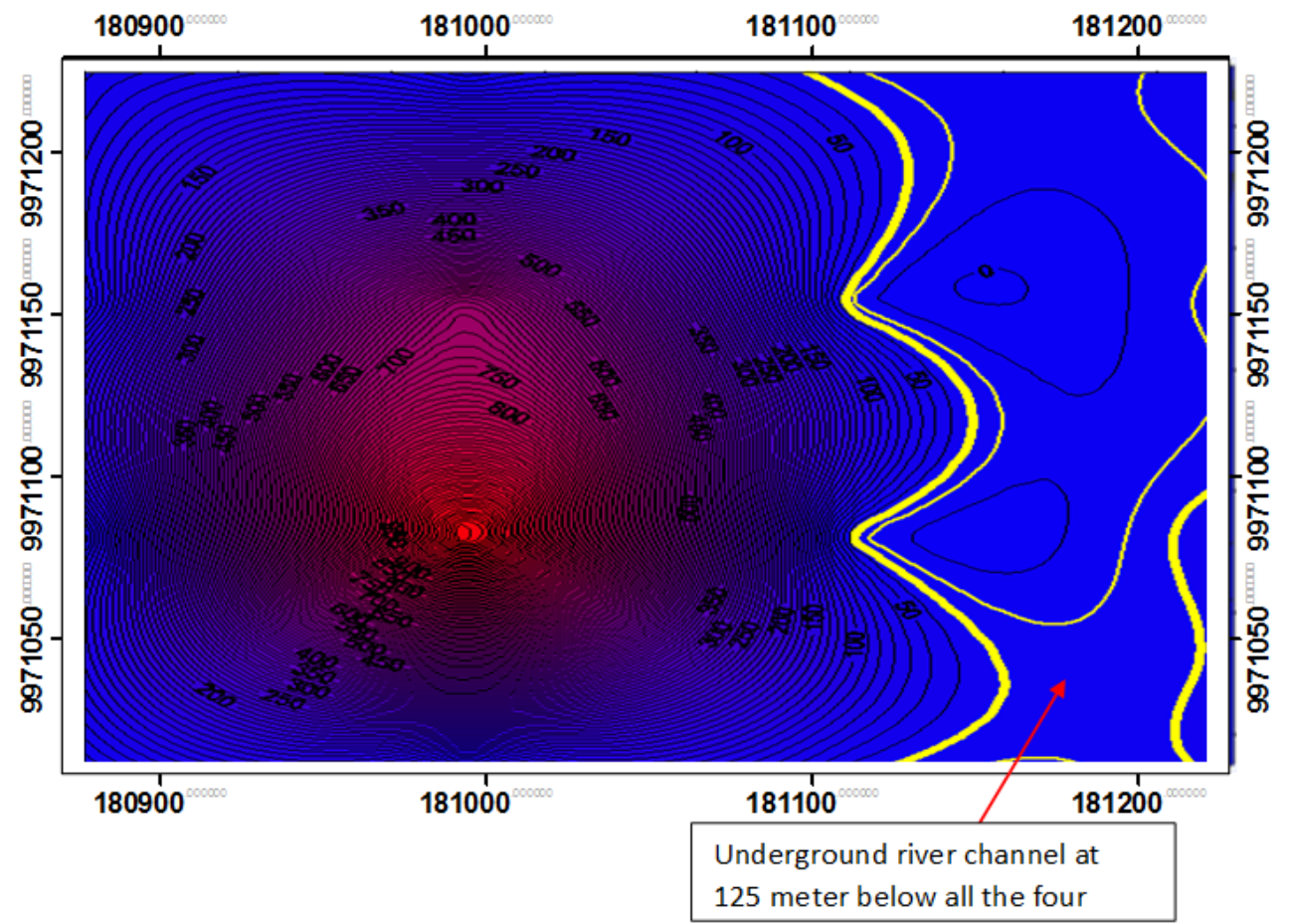

Figure 10. The Iso -Resistivity contour map at 125 meter depth for the Vertical electrical resistivity sounding. The river channel is geometrically oriented on the eastern part of the VES stations in north - south direction as indicated by $20 \mathrm{~m}$ and $30 \mathrm{~m}$ contour (marked yellow) 


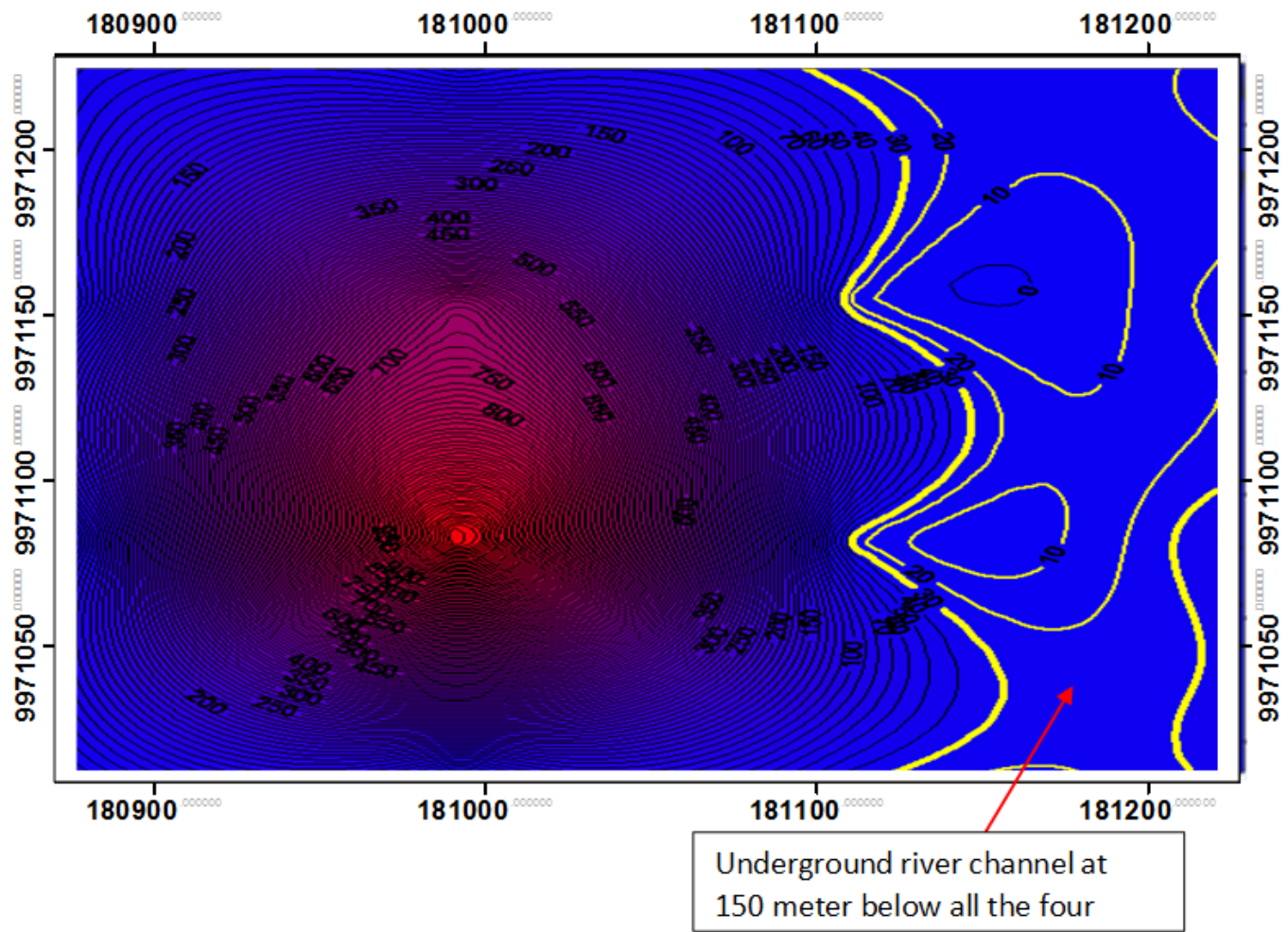

Figure 11. The Iso -Resistivity contour map at 150 meter depth for the Vertical electrical resistivity sounding. The river channel is geometrically oriented on the eastern part of the VES stations in north - south direction as indicated by $20 \mathrm{~m}$ and $30 \mathrm{~m}$ contour (marked yellow)

\subsubsection{Horizontal Iso-resistivity Map of the Area}

Apparent resistivity contours through two depth levels were constructed. The depth levels through which this contours were constructed are $125 \mathrm{~m}$ depth level and $150 \mathrm{~m}$ depth levels. Iso -resistivity maps (Figures 10 and 11) for these depth levels indicates the trend of low resistivity values concentrating on the eastern part of the Kabatini aquifer. The pattern of the low resistivity contours with southerly trend indicates the presence of a conductive media in the direction of NNS - SSE. The linear like conductive media is a river flowing at a a depth of 125 meters to 150 meters below the surface. The high resistivity contours that concentrate on the western side indicate the presence of an intrusion the goes down beyond 165 meter depth.

\section{Conclusions}

The results of investigations executed by the electrical resistivity method prove the existence of a relationship between the distribution of electric resistivity and the geological structure [13]. The area under study occurs in the great Kenyan rift valley. The Great Kenyan rift is oriented in the $\mathrm{N}-\mathrm{S}$ direction. Major faults in the area were caused by tensional stress. The Ngossur river channel occurring in the northern part of the study area disappears from the surface a few kilometers on the northern part of the study area. From this investigations, it can be concluded that the river disappears into a fault plane and flows underground in the $\mathrm{N}-\mathrm{S}$ direction towards Lake Nakuru.

Baharini aquifer occurs about $15 \mathrm{~km}$ to the $\mathrm{SSW}$ of Kabatini area. The orientation of the fault line trends towards Baharini springs which are found in Baharini aquifer. The investigation shows that the river channel identified in Kabatini flows deeper up to beyond 165 meters underground following the fault plane. In consideration of the direction of the fault plane and the river channel towards Baharini, it possible to conclude that the river channel in Kabatini feeds Baharini aquifer.

\section{Acknowledgements}

This research is part of my MSc. at the University of Nairobi. I wish to thank the University of Nairobi Kenya, for funding this research work inform of a scholarship during my Master program in the department of Geology (Waswa, [12]). I also thank Professor Justus Barongo of the department of Geology, University of Nairobi for supervising this research.

\section{REFERENCES}

[1] Clarke, M., Woodhall, D., Allen, D., and Darling, G. (1990). Geological, volcanological and hydrological controls of the 
occurrence of geothermal activity in the area surrounding Lake Naivasha. Technical report, Government of Kenya, Ministry of Energy/British Geological Survey.

[2] Michel, R., Jean-Claude, P., Diouf, S., Beauvais, A., Dione, F., and Dione, F. (1999). Electrical imaging of lateritic weathering mantles over granitic and metamorphic basement of eastern Senegal, West uppercase Africa. Journal of Applied Geophysics, 41:335-344.

[3] Dey, A. and Morrison, H. (1979). Resistivity modelling for arbitrary shaped two dimensional structures. Geophys. Prospect. 27:106-136.

[4] Koefoed O., (1979). Geosounding Principles 1: Resistivity sounding measurements. Elsevier Science Publishing Company, Amsterdam.

[5] Dey A. and Morrison H.F. (1979a). Resistivity modelling for arbitrary shaped two-dimensional structures. Geophysical Prospecting 27, 1020-1036.

[6] Keller G.V. and Frischknecht F.C., (1966). Electrical methods in geophysical prospecting. Pergamon Press Inc., Oxford.

[7] Daniels F. and Alberty R.A., 1966. Physical Chemistry. John Wiley and Sons, Inc. deGroot-Hedlin, C. and Constable, S., 1990. Occam's inversion to generate smooth, two dimensional models form magnetotelluric data. Geophysics, $55,1613-1624$

[8] Telford, W.M., Geldart, L.P. and Sheriff, R.E., (1990). Applied geophysics, 2nd edition, Cambridge University Press, Cambridge, 792p.

[9] Griffiths, D. and Baker, R. (1993). Two-dimensional resistivity imaging and modelling in areas of complex geology. Journal of Applied Geophysics, 29:211-226.

[10] Sporry, R. (2001). Lecture material on Resistivity. Earth System Analysis Department, ITC

[11] Zohdy, A., Eaton, G., and Mabey, D. (1974), Application of surface geophysics to groundwater investigations, Techniques of Water-Resources Investigation of the United States Geological Survey, Book 2, D1.

[12] Waswa A, K.(2010). Geophysical of mapping buried river channels and other shallow structures recharging major aquifers in the lake Nakuru basin Kenya rift, case study from Kabatini aquifer. http://erepository.uonbi.ac.ke/

[13] Zohdy, A.A.R. (1989) A new method for the automatic interpretation of Schlumberger and Wenner sounding curve, Geophysics 54(2):245- 25 